\title{
Editorial
}

\section{O editor como mediador}

\section{Editorial}

\section{The Editor as Mediator}

Ana Paula Sampaio CALDEIRA ${ }^{1}$ http://orcid.org/0000-0001-8313-1062

${ }^{1}$ Editora Chefe de Varia Historia

Universidade Federal de Minas Gerais

Av. Antônio Carlos 6627, Belo Horizonte, MG, 31.270-901, Brasil

anapaula.sampaiocaldeira@gmail.com

Este é o meu último número como editora chefe da Varia Historia. A tarefa de conduzir uma revista é, como o leitor pode imaginar, bastante trabalhosa, mas ela permite também muito aprendizado. Refiro-me a um tipo de aprendizado que não se resume somente à percepção mais clara acerca das demandas que se impõem aos periódicos de nossa área, advindas, por exemplo, dos indexadores e das agências de fomento. Essa visão, de fato, só se adquire quando passamos a conhecer por dentro o trabalho editorial. Mas a função de editor nos possibilita também um aprendizado de outra ordem, que envolve a percepção do papel fundamental das revistas como veículos de circulação e de democratização do conhecimento histórico. Esse papel se torna ainda mais evidente quando falamos do cenário brasileiro, pois aqui o financiamento público tem permitido a realização de pesquisas em nossa área e a publicização delas em periódicos gratuitos e de acesso aberto (Costa; Leite, 2016). Diante desse quadro, mais do que nunca é importante ressaltar que o funcionamento da Varia Historia nos dois anos em 
que estive à frente dela, e mesmo em períodos anteriores, se deveu ao apoio financeiro de agências como $\mathrm{CNPq}$, Capes e Fapemig, além do Programa de Pós-Graduação em História e da Faculdade de Filosofia e Ciências Humanas da UFMG.

O trabalho como editor permite, ainda, um outro aprendizado: o de entender o processo editorial a partir de um ponto de vista diferente. Não o do autor, que submete o artigo e aguarda pelo resultado da avaliação. Tampouco o do parecerista, no importante e difícil papel de avaliar os resultados da pesquisa de um colega. Mas, o ponto de vista daquele cuja tarefa é a de estabelecer um diálogo entre os diversos agentes envolvidos no processo editorial.

De maneira geral, o trabalho do editor é lembrado pelo seu poder de decisão e de definição em relação ao que será ou não publicado em um periódico. Ou seja, por aquilo que remete ao resultado final da revista pronta e disponibilizada ao público. Vale a pena lembrar, no entanto, que o trabalho do editor é anterior a isso, na medida em que ele age no que seria um ponto de convergência e também de tensão entre as expectativas dos autores, as orientações dos pareceristas, a missão da revista e as características próprias da área do conhecimento em que o periódico se insere. Por tudo isso, talvez seja possível entender a figura do editor como um mediador.

A necessidade de pensar o papel do editor e de conceber o seu lugar estratégico ao longo do processo editorial permeou os debates entre os estudiosos e representantes de diversas revistas científicas da área de história reunidos no Workshop de comemoração dos 25 anos da Revista História, Ciência e Saúde - Manguinhos, do qual a Varia Historia teve o prazer de participar. Na ocasião, aos participantes do evento discutiram o futuro dos periódicos da nossa área, o que, em princípio, nos remeteu a demandas muito presentes atualmente no cotidiano dos editores, tais como a internacionalização das revistas, a aceitação ou não de preprints e as possíveis mudanças no processo de avaliação dos manuscritos. Entretanto, o debate em torno do papel do editor esteve presente em vários momentos do evento, em especial na mesa dedicada ao tema da 
revisão por pares, que reuniu os pesquisadores Nelson Sanjad, Maria Luisa Sousa, Karina Ramacciotti e Stefan Pohl. ${ }^{1}$

A percepção do editor como um "mediador" foi trazida por Nelson Sanjad, particularmente, e reafirmada por outros participantes e ouvintes do evento. Parece-nos que o entendimento do trabalho de mediação desenvolvido pelo editor é uma questão primária e imprescindível para pensar a inserção dos periódicos de nossa área no movimento da ciência aberta, sobretudo porque este movimento vem sendo entendido como de "desintermediação" do acesso e da comunicação de informações (Parker; Santos, 2019). Porém, compreender o editor como mediador significa reconhecer o seu papel como aquele que busca fazer de um periódico um lugar de encontros, na feliz expressão utilizada por Nelson Sanjad. Portanto, a expectativa é que a atuação dele se desenvolva no sentido de contribuir para aquilo que seria a tônica de todo trabalho científico e intelectual: a colaboração entre os membros de uma comunidade. Nesse sentido, não há ciência sem mediação e, portanto, não há revista científica sem mediadores, uma vez que a mediação, longe de ser um problema, é constitutiva do campo em que atuamos. É fundamental aproveitarmos essa demanda em torno da inserção dos periódicos da nossa área aos pressupostos da ciência aberta para acentuarmos ainda mais esse caráter mediador das nossos revistas e de seus editores, ampliando espaços de discussão que nos ajudem a construir, coletiva e colaborativamente, como exige todo bom trabalho intelectual, o futuro dos periódicos científicos de nossa área.

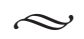

1 O Workshop de 25 anos da Revista História, Ciência e Saúde - Manguinhos ocorreu entre os dias 26 e 28 de junho, na sede da Fundação Oswaldo Cruz, no Rio de Janeiro. Para uma síntese das falas dos quatro participantes da mesa que discutiu a questão da revisão por pares, ver: Revisão por pares: entre o 'duplo-cego' e a transparência total do processo de avaliação de artigos. Blog de HCS-Manguinhos. Publicada em 26 de jul. de 2019. Disponível em http:// www.revistahcsm.coc.fiocruz.br/revisao-por-pares-entre-o-duplo-cego-e-a-transparencia-total-do-processo-de-avaliacao-de-artigos. Acesso em ago. de 2019. 
Ao concluir meu período à frente da Varia Historia, agradeço aos meus colegas do Programa de Pós-Graduação em História pela confiança depositada em mim e também aos autores e pareceristas, que contribuíram enormemente para que a revista mantivesse seu padrão de excelência e sua missão de divulgar pesquisas de qualidade e instigantes. Sou grata aos membros do Conselho Consultivo e, especialmente, aos meus colegas do Conselho Editorial, que acompanharam o cotidiano da revista, ajudando-me na tomada de decisões e na preparação de cada número. Faço uma menção especial ao Douglas Attila e às minhas colegas Anny Jackeline Silveira e Regina Horta pelo diálogo que mantivemos e por todo o apoio dado a mim nesse período. Por fim, agradeço aos alunos de graduação e de pós-graduação que compõem a equipe Varia Historia e que trabalharam com enorme dedicação na edição dos artigos, nas entrevistas do canal que mantemos no Youtube e no fortalecimento da presença da revista nas redes sociais: Jéssica Santomauro, Débora Cunha, Marina Colen, Maria Thereza Santana, Nathálya Ferreira, Giovanna Fernandes, Vivian Gomes, Ygor Gabriel Alves, Carolina Othero, Lêda Batista e Paula Oliveira.

À minha colega de departamento e amiga Silvia Liebel, que assumirá a editoria da revista daqui por diante, desejo muito boa sorte e sucesso na condução da Varia Historia. Que o trabalho de Silvia e de todo Conselho Editorial seja o de fortalecer este periódico como um importante lugar de encontro da área de História.

\section{REFERÊNCIAS BIBLIOGRÁFICAS}

Revisão por pares: entre o 'duplo-cego' e a transparência total do processo de avaliação de artigos. Blog de HCS-Manguinhos. Publicada em 26 de julho de 2019. Disponível em http://www.revistahcsm.coc.fiocruz. br/revisao-por-pares-entre-o-duplo-cego-e-a-transparencia-total-doprocesso-de-avaliacao-de-artigos. Acesso em ago. de 2019. 
COSTA, Michelli; LEITE, Fernando. Open Access in the World and Latin America: a Review since the Budapest Open Access Initiative. TransInformação, Campinas, n. 28, p.33-45, jan./abr. 2016. Disponível em: http:// dx.doi.org/10.1590/2318-08892016002800003. Acesso em jun. de 2019. PACKER, Abel; SANTOS, Solange. Ciência aberta e o novo modus operandi de comunicar pesquisa - Parte I. SciELO em Perspectiva, 2019. Disponível em: https://blog.scielo.org/blog/2019/08/01/ciencia-aberta-e-o-novo-modus-operandi-de-comunicar-pesquisa-parte-i/. Acesso em ago. de 2019. 